\title{
The Positivity of Anti-TPO and Anti-tTGA in Children with Type 1 Diabetes Mellitus in Albania
}

\author{
Margarita Kurti
}

University of Medicine, Albania.

DOI: https://doi.org/10.52403/ijhsr.20220122

\begin{abstract}
Background: Type 1 diabetes mellitus (T1 DM) is the most common type of diabetes in children. T1DM patients are also at higher risk of other comorbid autoimmune diseases, including autoimmune thyroid disease (AITD), celiac disease (CD). The thyroid-specific immune damage of AITD is strongly associated with elevated serum thyroid peroxidase (TPO). Tissue transglutaminase antibody (tTGA) is a specific antibody and a serological marker of CD.

This study aimed to evaluate the positivity of anti - TPO and anti - tTGA in children with T1DM after they were diagnosed.

Materials and Methods: This study was conducted from January 2019 to October 2020, included 105 children with T1DM. 44 children matching in aged (1 - 14 years) and gender were taken as control with other diagnoses (16 with viral infection, 24 with short stature, 4 with genetic disorders). The antibodies were checked up for the first time after they were diagnosed. Anti - TPO and anti tTGA were carried out by ELISA.

Results: 55.2\% of T1DM children were girls. The anti-TPO was positive in 30.5\% of T1DM children compared to $4.5 \%$ of children in control group. The anti-tTGA was positive in $7.6 \%$ of T1DM children compared to $2.3 \%$ of children in control group. Risk of Hashimoto's hypothyroidism was more in children older than 10 years old. $21.9 \%$ of children 11 - 14 years old were anti - TPO positive, but it was $16.2 \%$, more common in girls. While, anti - tTGA was positive in $3.85 \%$ of children 1 - 5 years old with no difference between boys and girls.

Conclusion The most frequent autoimmune disease resulted Hashimoto's hypothyroidism.

Girls with T1DM have a higher predisposition to Hashimoto's Hypothyroidism in the 11-14 age group compared to boys. Children with T1DM were found to have a lower predisposition to CD. Children with T1DM have a higher predisposition to develop CD at the age of $1-5$ years.

In conclusion we can say that antibodies to other autoimmune diseases must be performed together with diagnostic examinations for T1DM.
\end{abstract}

Keywords: Type 1 diabetes mellitus, Autoimmune Thyroid Disease, Celiac Disease, Thyroid Peroxidase, Tissue Transglutaminase Antibody.

\section{INTRODUCTION}

T1 DM is an autoimmune disorder that is the most type of diabetes in children and adolescents, arising through a complex interaction of immune, genetic and environmental factors (1). Data from European diabetes centers suggest that the annual rate of increase in T1 DM incidence is $2-5 \%$ up to $9 \%$. The overall prevalence of diabetes among school-age children is approximately 1.9 in 1000 . Girls and boys are almost equally affected (2). T1DM patients are also at higher risk of other comorbid autoimmune diseases, including AITD, CD. The thyroid-specific immune damage of AITD is strongly associated with elevated serum anti-TPO (3). Anti-TPO antibodies are found positive at the time of diagnosis of T1DM in $17-25 \%$ of cases. $30 \%$ of patients with T1DM are affected by 
Hashimoto's Hypothyroidism $(3,4,5,6)$. The incidence of $\mathrm{CD}$ in the general pediatric population varies from $1-5.5 \%$ (7). T1 DM is considered a strong risk factor for $\mathrm{CD}$. $\mathrm{CD}$ has been found in $0.97 \%$ to $16.7 \%$ of T1DM patients (8), a markedly higher rate than in nondiabetic patients. Anti-tTGA is a specific antibody of intestinal epithelial cells and a serological marker of CD. Autoimmune comorbidities can exacerbate T1DM symptoms and introduce additional complications (9). For instance, subclinical hypothyroidism or hyperthyroidism due to AITD will increase the probability of hypoglycemia in T1DM, making blood glucose control more difficult $(10,11)$. Similarly, the digestive tract symptoms of $C D$ can cause malnutrition, which will further disrupt blood sugar stability as well as stunt the growth and development of younger T1DM patients (12).

\section{Aim of the study}

Determination of anti - TPO and anti - tTGA antibodies in T1DM children and control group. Comparison of positivity for two antibodies, anti - TPO and anti - tTGA based on gender and age - groups.

\section{MATERIALS AND METHODS}

This study was conducted from January 2019 to October 2020, included 105 children who had just been diagnosed with T1DM.

The inclusion criteria for the diabetic group were: Type $1 \mathrm{DM}$ and aged between 1-14 years. The exclusion criteria included subjects with a positive history of previous thyroid disorders and $\mathrm{CD}$, patient with evident organ system disease.

As a control group were taken 44 children matching in aged ( $1-14$ years) and gender with other diagnoses (16 with viral infection, 24 with short stature, 4 with genetic disorders). The antibodies were checked up for the first time after they were diagnosed. Measurement of serum Anti TPO and anti - tTGA were carried out by ELISA using aesku. Diagnostics Kit. Levels have been defined according to the Kit used: Negative: < 12 IU/ml, Borderline: 12-18 IU/ml, Positive: > $18 \mathrm{IU} / \mathrm{ml}$.

\section{RESULTS}

All children were 1 - 14 years old $(9.4 \pm 10) .52 .4 \%$ of T1DM children were 11 - 14 years and 31.4\% were 6 - 10 years (table 2). Females were more affected than males $58(55.2 \%)$ versus $47(44.8 \%)$ with no statistical significance $(\mathrm{p}=0.7)$ (table 1$)$.

The anti-TPO positivity was $30.5 \%$ in T1DM compared to $4.5 \%$ in the control group, this difference was statistically significant $(\mathrm{p}=0.0004)$ (table 3$)$. The antitTGA positivity was $7.6 \%$ in T1DM compared to the control group 2.3\%, $\mathrm{P}$ value not significant $(\mathrm{p}=0.28)$ (table 4$)$. The prevalence of anti - TPO based on age group was higher $21.9 \%$ in the age group 11-14 years (table 5). The prevalence of anti-TPO based on age and gender was $16.3 \%$ in girls 11-14 years and $4.8 \%$ in girls $6-10$ years (table 5). While, the prevalence of anti tTGA was higher $3.85 \%$ in the children 1 - 5 years with no differences between the genders (table 6).

Table 1: Data of all children included based on gender
\begin{tabular}{|l|l|l|l|l|l|l|l|}
\hline \multirow{2}{*}{ Variables } & T1DM children & Control children & Total & P-value \\
\cline { 2 - 7 } & No & $\mathbf{\%}$ & No & \% & No & \% & \multirow{2}{*}{ P=0.7 } \\
\hline Male & 47 & $\mathbf{4 4 . 8}$ & 18 & $41 \%$ & 65 & $43.6 \%$ & \\
\hline Female & 58 & $\mathbf{5 5 . 2}$ & 26 & $59 \%$ & 84 & $56.4 \%$ & \\
\hline Total & 105 & & 44 & & 149 & & \\
\hline
\end{tabular}

Table 2: Data of T1 DM children based on gender and age-group

\begin{tabular}{|c|c|c|c|c|c|c|c|}
\hline \multicolumn{8}{|c|}{ T1DM Children } \\
\hline \multirow[b]{2}{*}{ Variables } & \multicolumn{2}{|c|}{$0-5$} & \multicolumn{2}{|c|}{$6-10$} & \multicolumn{2}{|c|}{$11-14$} & \multirow[t]{2}{*}{ Total } \\
\hline & No & $\%$ & No & $\%$ & No & $\%$ & \\
\hline Male & 11 & $10.4 \%$ & 15 & $14.3 \%$ & 21 & $20 \%$ & 47 \\
\hline Female & 6 & $5.7 \%$ & 18 & $17 \%$ & 34 & $32.4 \%$ & 58 \\
\hline Total & 17 & $16.2 \%$ & 33 & $31.4 \%$ & 55 & $52.4 \%$ & 105 \\
\hline
\end{tabular}


Margarita Kurti. The positivity of anti - TPO and anti - tTGA in children with type 1 diabetes mellitus in Albania.

Table 3: The positivity of anti-TPO in T1 DM children and control group

\begin{tabular}{|c|c|c|c|c|c|c|c|}
\hline \multirow[b]{2}{*}{ Variables } & \multicolumn{2}{|c|}{ T1DM children } & \multicolumn{2}{|c|}{ Control children } & \multicolumn{2}{|c|}{ Total } & \multirow{2}{*}{\begin{tabular}{|l|}
$P$-value \\
$P=0.0004$
\end{tabular}} \\
\hline & No & $\%$ & No & $\%$ & No & $\%$ & \\
\hline Anti - TPO neg & 73 & 69.5 & 42 & 95.5 & 115 & 77.2 & \\
\hline Ant & 32 & 30.5 & 2 & 4.5 & 34 & 22.8 & \\
\hline Total & 105 & 100 & 44 & 100 & 149 & 100 & \\
\hline
\end{tabular}

Table 4 : The positivity of anti-tTGA in T1 DM children and control group

\begin{tabular}{|l|l|l|l|l|l|l|l|}
\hline \multirow{2}{*}{ Variables } & \multicolumn{2}{|l|}{ T1DM children } & \multicolumn{2}{|c|}{ Control-children } & \multicolumn{2}{|c|}{ Total } & P-value \\
\cline { 2 - 7 } & No & \% & No & \% & No & \% & \multirow{2}{*}{ P=0.28 } \\
\hline Anti - t-TGA neg & 97 & 82.4 & 43 & 97.7 & 140 & 94 \\
\hline Anti - t-TGA pos & 8 & $\mathbf{7 . 6}$ & 1 & $\mathbf{2 . 3}$ & 9 & 6 \\
\hline Total & 105 & & 44 & & 149 & & \\
\end{tabular}

Table 5: The positivity of anti-TPO based on gender and age-group

\begin{tabular}{|c|c|c|c|c|c|c|c|}
\hline \multirow[b]{3}{*}{ Variables } & \multicolumn{2}{|c|}{ T1DM children } & \multicolumn{4}{|c|}{ Anti-TPO positive } & \\
\hline & \multicolumn{2}{|c|}{$0-5$} & \multicolumn{2}{|c|}{$6-10$} & \multicolumn{2}{|c|}{$11-14$} & \multirow[t]{2}{*}{ Total } \\
\hline & No & $\%$ & No & $\%$ & No & $\%$ & \\
\hline Male & 0 & $0 \%$ & 3 & $2.9 \%$ & 6 & $5.7 \%$ & 9 \\
\hline Female & 1 & $0.9 \%$ & 5 & $4.8 \%$ & 17 & $16.2 \%$ & 23 \\
\hline Total & 1 & $0.9 \%$ & 8 & $7.6 \%$ & 23 & $21.9 \%$ & 32 \\
\hline
\end{tabular}

Table 6: The positivity of anti-tTGA based on gender and age-group

\begin{tabular}{|c|c|c|c|c|c|c|c|}
\hline & \multicolumn{2}{|c|}{ T1DM childre } & \multicolumn{4}{|c|}{ Anti-tTGA positive } & \multirow{3}{*}{ Total } \\
\hline \multirow[b]{2}{*}{ Variables } & \multicolumn{2}{|c|}{$0-5$} & \multicolumn{2}{|c|}{$6-10$} & \multicolumn{2}{|c|}{$11-14$} & \\
\hline & No & $\%$ & No & $\%$ & No & $\%$ & \\
\hline Male & 1 & $0.95 \%$ & 0 & $0 \%$ & 1 & $0.95 \%$ & 2 \\
\hline Female & 3 & $2.9 \%$ & 2 & $1.9 \%$ & 1 & $0.95 \%$ & 6 \\
\hline Total & 4 & $3.85 \%$ & 2 & $1.9 \%$ & 2 & $1.9 \%$ & 8 \\
\hline
\end{tabular}

\section{CONCLUSION}

T1DM affects children without age predisposition $\mathrm{F}$ : $\mathrm{M}$ ratio is $1: 1.2$. The present study confirmed higher incidence rate of Hashimoto's hypothyroidism. in children and adolescents suffering from type 1 DM. All the children were more than 10 years of age, indicating increased risk of Hashimoto's Hypothyroidism with increasing age.

Girls with T1DM have a higher predisposition to Hashimoto's Hypothyroidism in the 11-14 age group or starting at 6-14 years compared to boys. Children with T1DM were found to have a lower predisposition to Celiac disease. Children with T1DM have a higher predisposition to develop Celiac disease at the age of $1-5$ years.

In conclusion we can say that antibodies to other autoimmune diseases should be sought in parallel with diagnostic examinations for T1DM. In cases where antibodies are not present at the time of diagnosis of T1DM, screening every 6-12 months is recommended.

\section{Acknowledgement: None}

Conflict of Interest: None declared

\section{Source of Funding: None}

Ethical Approval: Approved

\section{REFERENCES}

1. Zamanfar D, Aarabi M, Sadeghian I. Type 1 Diabetes Mellitus Associated with Autoimmune Thyroid Disorder in Iranian Children: A Review, Pediatric Rev; 2015. 3(1):e157.

2. Cooper D, McDermott M, Wartofsky L. Hypothyroidism, J Clin Endocrinol Metab, 2004.89 (11): E2.

3. Boelaert $\mathrm{K}$ and Franklyn JA. Thyroid hormone in health and disease, Journal of Endocrinology, 2005.187:1-15.

4. Hage M, Mira SZ, Azar ST. Thyroid Disorders and Diabetes Mellitus, Journal of Thyroid Research Volume 2011; 439463: 7.

5. Husebye ES, Anderson MS, Kampe O (2018) Autoimmune polyendocrine syndromes. N Engl J Med 378: 1132-1141.

6. Svoren BM and Nicholas J. Type 1 Diabetes Mellitus (Immune Mediated): Nelson Textbook of pediatrics 20th ed.2016. Chap: 589; 2: 2763-77.

7. Yuan J, Zhou C, Gao J, Li J, Yu F, et al. (2017) Prevalence of celiac disease autoimmunity among adolescents and young 
Margarita Kurti. The positivity of anti - TPO and anti - tTGA in children with type 1 diabetes mellitus in Albania.

adults in China. Clin Gastroenterol Hepatol 15: 1572-1579. e1.

8. Kaspers S, Kordonouri O, Schober E, Grabert M, Hauffa BP, et al. (2004) Anthropometry, metabolic control, and thyroid autoimmunity in type 1 diabetes with celiac disease: a multicenter survey. J Pediatr 145: 790-795.

9. Manso J, Pezzani R, Scarpa R, Gallo N, Betterle C (2018) The natural history of autoimmune Addison's disease with a nonclassical presentation: a case report and review of literature. Clin Chem Lab Med 56: 896-900.

10. Mohn A, Di Michele S, Di Luzio R, Tumini S, Chiarelli F (2002) The effect of subclinical hypothyroidism on metabolic control in children and adolescents with type 1 diabetes mellitus. Diabet Med 19: 70-73.
11. Dost A, Rohrer TR, Frohlich-Reiterer E, Bollow E, Karges B, et al. (2015) Hyperthyroidism in 276 children and adolescents with type 1 diabetes from Germany and Austria. Horm Res Paediatr 84: 190-198.

12. Frohlich-Reiterer EE, Hofer S, Kaspers S, Herbst A, Kordonouri O, et al. (2008) Screening frequency for celiac disease and autoimmune thyroiditis in children and adolescents with type 1 diabetes mellitusdata from a German/Austrian multicentre survey. Pediatr Diabetes 9: 546-553.

How to cite this article: Margarita Kurti. The positivity of anti - TPO and anti - tTGA in children with type 1 diabetes mellitus in Albania. Int J Health Sci Res. 2022; 12(1):157160. DOI: https://doi.org/10.52403/ijhsr. 20220122 